\title{
A POLISSEMIA EM TORNO DO VOCÁBULO PAYS/PAÍS: ENTRE ESCALAS, ESTADOS E NAÇÕES
}

\author{
THE POLYSSEMY AROUND PAYS/COUNTRY: \\ BETWEEN SCALE, STATES AND NATIONS \\ LA POLYSÉMIE AU TOUR DE PAYS/PAYS: \\ ENTRE ECHELLES, ETATS ET NATIONS
}

\author{
Rogata Soares Del Gaudio - Universidade Federal de Minas Gerais - Belo Horizonte - Minas Gerais - Brasil \\ rogatasoares@gmail.com \\ Doralice Barros Pereira - Universidade Federal de Minas Gerais - Belo Horizonte - Minas Gerais - Brasil \\ pereiradb@yahoo.com.br
}

\section{Resumo}

0 presente artigo explora a polissemia do vocábulo país, tendo como referencial teórico a análise do discurso. As fontes de análise compreenderam uma revisão bibliográfica e as manifestações desse termo associadas às respostas sobre nação e estado nacional, em entrevistas com quatorze professores de escolas públicas e privadas de nível médio, em Belo Horizonte. A palavra país, ao ser aplicada tanto para se referir à nação quanto ao estado nacional, dispensa definições mais precisas e exatamente por isso ganha plasticidade, e sua utilidade torna-se conveniente, gerando consensos. Aí reside seu potencial para a produção de sentidos que faculta aos seres humanos um sentimento de pertencimento a mundos sócio-históricos. Simultaneamente, a utilização do termo país permite aos sujeitos (re)construírem suas identidades ligadas aos espaços - lugares de nascimento, estados/províncias, regiões, estados/nacionais.

Palavras-chave: geografia, polissemia, país, análise do discurso.

\section{Abstract}

This article explores the different meanings of the word country, having discourse analysis as a theoretical basis. The sources of analysis included a literature review and manifestations associated with this term from answers about nation and national state, in interviews with 14 teachers from public and private schools in Belo Horizonte. The word country, applied both to refer to the nation and to national state, spares more precise definitions, and because of that gets a plasticity aspect, whose usefulness becomes convenient, generating consensus. Therein lies its potential to produce meanings that provides humans with a sense of belonging to the socio-historical world. Simultaneously, the word country allows individuals to (re)construct their identities linked to spaces places of birth, states / provinces, regions and national states.

Keywords: geography, polissemy, country, discourse analyzes.

\section{Résumé}

Le présent article explore la polysémie du vocable pays, ayant l'analyse du discours comme cadre théorique. Les sources d'analyse ont inclus une révision bibliographique et les manifestations de ce terme associées aux réponses données sur nation et État national, dans des entretiens réalisés avec 14 professeurs de lycées publics et privés de Belo Horizonte. Le mot pays, en étant employé autant pour se référer à la nation qu'à l'État national, dispense de définitions plus précises et, à cause de cela justement, gagne en plasticité, dont l'utilité devient commode engendrant des consensus. En cela réside son potentiel pour une production de sens qui procure aux êtres humains un sentiment d'appartenance au monde socio-historique. Simultanément, pays permet aux sujets de (re)construire leurs identités liées aux espaces - lieux de naissance, États/provinces, régions, États-nationaux.

Mots-clés: géographie, polysémie, pays, analyse du discours. 


\section{Introdução}

As reflexões presentes neste artigo exploram as conotações e denotações (McLellan, 1987, p. 116) do termo país. A polissemia assume uma amplitude de significações e espacialidades, bem como conceituações homogeneizantes e delimitações espaciais. Em país, a série de significados indica imprecisões, mas, simultaneamente, comporta consensos e aponta para "visões sociais de mundo" (Löwy, 2002) hegemônicas. Já o dissenso pode promover o exercício da política em suas habilidades e potencialidades de negociação, explicitar um campo de forças e irromper apontando diferenças reais entre atores e projetos sociais (Rancière, 1996).

Neste estudo, procedemos a uma revisão bibliográfica e a entrevistas com quatorze docentes de Geografia, de sete escolas de nível médio de Belo Horizonte, sendo duas privadas confessionais, uma privada de caráter empresarial, duas públicas estaduais e duas públicas municipais (Del Gaudio, 2006). A seleção das escolas foi feita com base nas pesquisas da Comissão Permanente do Vestibular - COPEVE (Boletim da UFMG, 1997; 2004) -, realizadas em 1997 e 2003, que identificaram essas escolas públicas e privadas como as de maior impacto na formação dos estudantes, resultando no seu ingresso na UFMG.

Da pesquisa bibliográfica emergiu a pluralidade conferida ao vocábulo em línguas ocidentais, a exemplo do português, inglês e francês, e daí surgiu a necessidade de se identificarem questões socioespaciais do termo entre saberes científicos e não científicos. Em uma só palavra, como termo chave, país intermedeia a apreensão de mundos, cosmologias e suas diversidades, aproximando representações e funções. Apoiadas em Mikhail Bakhtin, consideramos que

a palavra é o signo ideológico por excelência. A realidade toda da palavra é absorvida por sua função de signo. A palavra não comporta nada que não esteja ligado a essa função, nada que não tenha sido gerado por ela. A palavra é o modo mais puro e sensível de relação social. (Bakhtin, 2006, p. 36)

A análise das entrevistas evidenciou a polissemia e o hibridismo da palavra país. A polissemia, para Bakhtin, evoca a multiplicidade dos sentidos da palavra, tendo em conta que ela existe - se materializa, manifesta e ocorre - sob as formas: a palavra no/do dicionário, a palavra do outro e a palavra pessoal (Castro, 2002). Já a hibridização retém 
uma mistura de duas linguagens sociais dentro dos limites de um único enunciado; um encontro, dentro da arena de um enunciado, entre duas consciências linguísticas diferentes, separadas uma da outra por uma época, pela diferenciação social ou por algum outro fator. (Bakhtin, 1981, p. 358, citado em Pagano e Magalhães, 2005)

País constitui um vocábulo que remete a algo para além de si mesmo, que une tempos e espaços diferentes e possibilita aos sujeitos se compreenderem como parte dos mundos sócio-históricos (Therborn, 1991), pois, segundo Orlandi, “as ideias não têm um lugar, têm muitos” (1993, p. 7). Assim, Bhabha explica o hibridismo como

a mímica ou [...] signo de uma articulação dupla, uma estratégia complexa de reforma, regulação e disciplina que se "apropria" do Outro ao visualizar o poder. [...] Signo do inapropriado [...] uma diferença [...] que ordena a função estratégica dominante do poder colonial, intensifica a vigilância e coloca uma ameaça imanente tanto para os saberes "normalizados" quanto para os poderes disciplinares. (Bhabha, 1998, p. 130)

Construir a historicidade dos processos discursivos afeitos a país conduz a "pensar como os processos discursivos se relacionam. Como uns vão se construindo em relação aos outros” (Orlandi, 1993, p. 23). País pode ser um híbrido, porque, apesar de na Europa, em especial na França, ter surgido com significado geográfico bastante restrito - como o lugar, o cantão -, seu sentido foi amplamente modificado, e atualmente designa, na Geografia e em outras ciências humanas, conceitos distintos, como nação e estado nacional, sem fundi-los; e, ainda, cria uma comunidade de sentido ao seu redor.

Ao aplicar essa palavra, um quase consenso acerca do fenômeno/ espaço/território referidos se instaura. É de se indagar, então, se esse processo estimularia a produção de exclusões, cartografias omissas, novos totalitarismos, fundamentalismos e colonização.

País parece adaptável a qualquer contexto e escala, fecunda (in)determinações de usos/ocultações e expressa um discurso mnemônico. É um termo tão corriqueiro, tão intensamente agregado ao nosso vocabulário que sequer pressupomos que ele careça de qualquer definição. Ao contrário, de antemão pensamos que, ao empregá-lo, estabelecemos com nossos interlocutores uma "comunidade de sentido". Nessa condição, explicar o que entendemos por país seria até mesmo uma redundância, pois 
supomos que todos saibam o que o vocábulo significa e o que ele denota precisamente.

Na realização da pesquisa de doutorado (Del Gaudio, 2006), nosso interesse era discutir o que os professores de Geografia entrevistados concebiam acerca dos conceitos de nação e estado nacional. Porém, o termo país emergiu das colocações, que o relacionavam a esses dois conceitos e o adotavam para se referir ora a um, ora a outro. Então, indagamos: por que essa palavra e o que ela pode indicar?

\section{0 termo país em alguns dicionários e expoentes da Geografia}

Entre os estudiosos que colaboraram com conceitos e categorias para o desenvolvimento do fazer e do pensar geográfico, Vidal de La Blache agrega uma participação ímpar. Em suas elaborações, ele pontua que

a palavra pays é uma palavra muito antiga, repetida com muita frequência em sua acepção popular. Não significa uma extensão, uma zona [contrée] qualquer. No pensamento daqueles que a empregam, há um significado que remete a uma zona [contrée] determinada. Se o povo da França conhece alguns pays, se sabe distingui-los e guarda uma impressão bastante duradoura a ponto de essas denominações tão populares se perpetuarem sem ser consagradas pelas divisões administrativas ou oficiais, é porque tais nomes se associam, em seu espírito, a modos de habitação, de alimentação, de vestuário, de linguagem. Em uma palavra, associam-se a formas de viver que, para ele, são inseparáveis. (La Blache, 1904, em Haesbaert et al., 2012, p. 230)

Nessa conferência, ele evoca pays para além de "certas paisagens e territórios familiares", agregando usos e costumes e sugerindo formas de apego ao solo pátrio - ou à sua acepção de região. Aparecem ainda elementos físicos na sua exposição, bastante apropriados pelos geólogos e geógrafos quanto à fertilidade de planícies e exuberância de florestas, que distinguem lugares, aproximando-se da definição de região que o autor defende.

O uso frequente de dicionários em sala de aula levou-nos também a consultá-los, tanto em português, quanto nas línguas francesa e inglesa.

Segundo o Le Petit Robert (2000), dicionário de língua francesa, o termo pays foi criado em 1360, associando-se à "pessoa" e à "origem", ou melhor, ao lugar de origem de certa pessoa. Nesse dicionário, que registra 
o habitante de um pagus, de um canton, país comporta certa familiaridade entre pessoa e terra, incitando a uma afetividade entre as pessoas e destas com o seu entorno.

Portanto, inicialmente, o termo país engendra uma relação dos indivíduos entre si, e destes com sua origem comum e seu "cantão ou rincão". Remete, desse modo, a uma categoria geográfica que evidencia, entre outros aspectos, a afetividade e o vínculo profundo entre as pessoas de uma mesma coletividade (sua história, suas experiências, desafios, desejos e projetos políticos), e destas com seu entorno. O lugar é

o quadro de uma referência pragmática ao mundo, do qual lhe vêm solicitações e ordens precisas de ações condicionadas, mas é também o teatro insubstituível das paixões humanas, responsáveis, através da ação comunicativa, pelas mais diversas manifestações da espontaneidade e da criatividade. (Santos, 1999, p. 258)

Entender o lugar por meio de nossas necessidades implica localizar, mobilizar, relacionar-se com os objetos e com as pessoas - é a nossa corporeidade e, a partir dela, o nosso estar no mundo. O lugar articula as ordens objetiva e subjetiva, as relações verticais oriundas do poder hegemônico e as relações horizontais de coexistência e resistência (Moreira, 2007).

Por conseguinte, a associação entre lugar e nação, como "vínculo profundo entre os nacionais" (Anderson, 2008, p. 32-33), pode ser compreendida e explicada. A nação moderna, partícipe do concerto mundial de nações, assenta-se sobre a "dissolução do reino dinástico", a "substituição da língua sagrada pelas línguas nacionais”, a partir da constituição do "capitalismo de imprensa” (op. cit). Esses eventos afetam a própria concepção de país, atrelando-o à ideia moderna de nação-estado e à posse soberana de um território, apreendendo-o como

resultado de uma ação conduzida por um ator sintagmático (ator que realiza um programa) em qualquer nível. Ao se apropriar de um espaço, concreta ou abstratamente (por exemplo, pela representação), o ator "territorializa” o espaço. [...] O território, nessa perspectiva, é um espaço onde se projetou um trabalho, seja energia e informação, e que, por consequência, revela relações marcadas pelo poder. (Raffestin, 1993, p. 143-144)

Em relação ao território, sua dimensão política do/no espaço implica relações de poder, cuja materialização ocorre por meio das práticas sociais 
(Haesbaert, 2009, p. 104-105). As decisões sobre os usos e o destino de um território variam conforme distintos contextos econômicos, políticos, de conhecimento, e as redes de relações e poder. Neles, as visões sociais de mundo (Löwy, 2002) expressam práticas sociais e materializam-se dialeticamente no espaço-tempo. O território implica poder, não apenas o tradicional "poder político", mas o poder mais concreto, de dominação, e o poder mais simbólico, de apropriação. Assim, o território, como "espaço-tempo vivido", é sempre múltiplo, "diverso e complexo", ao contrário do território "unifuncional” proposto pela lógica capitalista hegemônica (Haesbaert, 2005). Privilegiar essa definição é de ordem política, pois território aparece atrelado à constituição dos estados nacionais territoriais.

Para Lacoste (1997), o elo entre o vocábulo país e sua origem latina (pagus) determinaria "um pequeno espaço geográfico, aquele do cantão, que se estende por uma dezena de quilômetros em torno de um mercado, um burgo ou uma pequena vila. [...] É o país natal, a terra do pai, a pátria em seu sentido primeiro" (op. cit., p. 136). E, ainda, "após as cruzadas, o significado da palavra país progressivamente se alarga, a ponto de designar desde extensões consideráveis até estados com seu território e sua população" (op. cit., p. 137). Então, país, lançado à conotação de estado, aciona uma acepção mais política e insufla atributos afeitos à soberania, unidade e liberdade. Na imbricação pays e nação, singularidades do território, língua e poder podem realçar rivalidades, concorrências entre eles e, portanto, hierarquias. A imprecisão em torno da palavra país explicaria

o sucesso escolar e diplomático da palavra, pois ela evita fazer alusões ao status político de um Estado e de sua população (trata-se de um reino, um império, uma república?), ou à questão de sua independência: uma colônia não é um Estado, mas um país, e seus colonizadores podem recusar a consideração de sua população como nação. (Lacoste, 1997, p. 137)

Esse autor sublinha que país aparece pela primeira vez definido no Dicionário da Academia Francesa (1694) e aglutina progressivas mudanças em sua escala, a partir da Revolução Francesa, até aliar-se à ideia de nação. Lacoste (1997), igualmente, esclarece que a concepção da palavra emerge na Declaração de Independência dos Estados Unidos da América, de 1776, na qual não se registra a palavra "nação". A palavra "nação" será utilizada por Abraão Lincoln em suas declarações precedentes à Guerra de Secessão. 
Na língua francesa, a despeito da historicidade do vocábulo e de sua ligação paulatina à ideia de pátria e nação, pays se mantém como termo relativamente impreciso. A pátria apresenta-se mais sujeita aos "sentimentos", enquanto nação seria um termo mais "oficial" (Lacoste, 1997, p. 139). Tal nuance permite aferir a dualidade dessa palavra, simultaneamente semióforo e termo híbrido. É preciso dizer que semióforo se refere a um signo trazido à frente ou empunhado para indicar algo que significa alguma outra coisa e cujo valor não é medido por sua materialidade e sim por sua força simbólica [...]. Um semióforo é fecundo porque dele não cessam de brotar efeitos de significação”. (Chauí, 2000, p. 12)

A palavra país constitui um semióforo ao lhe serem adicionadas novas significações, a exemplo do que faz o dicionário Larousse (1989), no qual pays designa tanto o território de uma nação, quanto o Estado; o conjunto de habitantes de uma nação; associa-se à ideia de região como espaço físico, climático, econômico etc. e remete ao lugar ou região de origem de alguém ou algum produto. O Larousse (1989) também apresenta pays como pessoa do mesmo vilarejo, da mesma região. Por exemplo, se uma pessoa está fora do Brasil e encontra um brasileiro, usa ou poderá usar a expressão "encontrar o país". O/A paysan/paysanne é definido como pessoa do campo, que vive do trabalho da terra. O dicionário registra que os sinônimos agricultor, cultivador e trabalhador agrícola são mais utilizados por causa do valor negativo do termo paysan.

Em inglês, o Collins Thesaurus of the English Language (2002) registra semelhanças e sinônimos com os dicionários de francês consultados, trazendo ainda outros significados: terra, solo, nação, possessão territorial ou propriedade. Nele, alude-se a outros aspectos advindos do hibridismo: à desobediência civil que atiraria à prisão; ao contrato de terra e à descendência, remetendo ao domínio de superfícies de terra, mar e lagos; ao contraste entre áreas rurais agrícolas em relação às áreas urbanas.

Em geografia, a despeito da frequência do uso de país, somente dois autores, em obras mais acadêmicas, entre os vários consultados, procuraram defini-lo com maior precisão nos sentidos eleitos (Magnoli, 1997; Lacoste, 1997). Segundo Magnoli (1997),

o termo não significou sempre o que significa hoje. De origem medieval, país designava apenas a "terra natal", habitada por uma coletividade limitada, ou, ainda, a população de uma região, os habitantes ligados por vínculos sociais e culturais que compartilhavam um ambiente. [...] Na origem desses termos [pays, paysan, 
paysage] o elo entre a população e a terra natal era unicamente um elo prático - a atividade cotidiana do trabalho no campo, ritmada pelas estações da natureza, criadora de paisagens rurais. (Magnoli, 1997, p. 13-14)

Para ele, "a possibilidade principal [de sentido para essa palavra inclusão nossa] consiste na acepção contemporânea, que está ancorada no fato político e associa país ao território nacional” (Magnoli, 1997, p. 14).

Todas as consultas aos dicionários, porém, foram insuficientes para explicar como essa palavra permaneceu agregada às ciências humanas em geral e à geografia em particular, e, ainda, como seu sentido original foi sendo transformado.

Assim, passamos a analisar as definições de país em obras de referência como o Dicionário de Política, organizado por Norberto Bobbio; a L'enciclopédia della Geografia, do Instituto Geográfico De Agostini, 1996, Novara, Itália; e a Enciclopédia Einaudi. Mas em nenhuma dessas obras encontramos definição desse vocábulo ou orientação acerca da construção de seus possíveis sentidos e significados.

Voltamo-nos, então, aos dicionários de língua portuguesa, em busca dos sentidos mais comuns de país, e pudemos perceber que as definições foram vagas e se referiam ora à nação como lugar de origem dos sujeitos, ora ao estado nacional territorial. No Novo Dicionário Aurélio da Língua Portuguesa, país é definido como

[Do lat. pagense (subentendido agru), 'território rural', 'país', atr. do fr. pays.] S.m. 1. Região, terra, território [...]. 2. Pátria, terra. 3. Território habitado por uma coletividade, e que constitui uma realidade histórica e geográfica com designação própria; nação [...]. 4. Meio ambiente, clima [...]. 5. Fig. Região, terra, lugar: o país das quimeras; o país dos sonhos. 6. Jur. Conjunto formado de povo e território, não chegando a constituir um Estado, por lhe faltar soberania ou governo independente. [Pl.: países.]. (Ferreira, 1986, p. 1247)

Essa gama de sentidos para país, nesse dicionário, remete de imediato às escalas da palavra, simultaneamente, terra, região, território, soberania (atributo dos estados nacionais territoriais no mundo ocidental, pelo menos desde os Tratados de Westfalia, 1648), meio ambiente/clima. Ao serem evocados, regiões e territórios - Minas Gerais/Brasil -, sobressai uma personalização/antropomorfização dos territórios e lugares ("O” Brasil; “das” Gerais; “o” país). A antropomorfização, mecanismo forte de 
interpelação, auxilia na identificação dos nacionais/regionais para dentro e em sua diferenciação para fora (Del Gaudio, 1998; 2006). No Dicionário Houaiss da língua portuguesa, país equivale a:

País - S. m. (sXV) 1. Qualquer região, terra ou território. 2. Território geograficamente delimitado e habitado por uma coletividade com história própria [...]. 3. Comunidade social e política à qual pertence; pátria, terra [...]. 4. Conjunto de habitantes de uma nação [...]. 5. Conjunto de condições materiais, culturais, psicológicas e morais que envolve as pessoas; ambiente, meio [...]. 6. Fig. Area de limites indefinidos; terra, lugar [...]. [...] Etim. fr. pays, 'região, país' do lat. tar. pagensis, 'aldeão'. (Houaiss, Villar, Franco, 2009, p. 1413)

Há, no Houaiss, uma aproximação entre país, nação e estado nacional territorial. A relativa proximidade entre as concepções de país nesses dois dicionários coaduna-se com a de Guibernau (1997), de matriz weberiana, quanto ao conceito de nação:

Um grupo humano consciente de formar uma comunidade e de partilhar uma cultura comum, ligada a um território claramente demarcado, tendo um passado e um projeto comuns e a exigência do direito de se governar. Desse modo, a nação inclui cinco dimensões: psicológica (consciência de formar um grupo), cultural, territorial, política e histórica. (Guibernau, 1997, p. 56)

Os conteúdos desses dicionários reportaram-nos aos de língua francesa, que exigem a explicação da etimologia da palavra. Os dicionários de etimologia Ernout e Meillet (1939), Bueno (1968), Cunha (1982) e Machado (1987) conferiram a país os sentidos de "lugar de nascimento," "terra natal," "burgo/aldeia," “nação," “estado," "região," "solo natal”. Notamos, assim, que os dicionários de língua portuguesa trazem para o termo significados derivados de seu sentido etimológico, ou seja, "país natal, solo natal".

\section{A "descoberta do país": a pesquisa com docentes da educação básica}

Por geografia escolar, Carneiro (2002) entende o conjunto de informações, métodos e técnicas voltados para a construção do raciocínio geográfico em crianças e jovens, na escola.

Entendemos ainda que existem diferenças entre os saberes acadêmicos/científicos e os saberes escolares/ensinados, posto que ambos respondem a finalidades distintas. Para Francisco Lestegás, os saberes científicos 
se alimentam dos problemas aos quais a ciência deve oferecer alguma resposta [...]; em contrapartida, o conhecimento escolar se organiza em torno de resultados, uma vez que é dirigido a determinados alunos em função de uma aprendizagem que devem realizar. Ambos diferem ainda em relação ao tipo de organização específica de seus textos. As elaborações científicas se apresentam através de uma grande diversidade de documentos, considerando suas finalidades, regras, condições de produção e destinatários. Em relação aos saberes escolares, estes abarcam sínteses de diferentes extensões e possuem caráter mais ou menos divulgativo. [...] No caso dos saberes ensinados, pode-se optar por textos fechados e marcados com signos que indiquem claramente aos alunos o que é importante e, portanto, o que devem aprender. (Lestegás, 2002, p. 173-174)

As relações entre ambos os conhecimentos geográficos - científico e escolar - geram uma "relação circular", pois um justifica e mantém a atualidade e necessidade do outro. Dessa reciprocidade, em que medida se constata a produção de sentido para a palavra país no âmbito da geografia escolar, e, a partir dela, como se dissemina para a sociedade em geral?

A fim de melhor esclarecer tal questão, analisamos seis categorias extraídas das entrevistas realizadas com quatorze professores de Geografia do ensino médio. Nas entrevistas, eles foram instigados a definir país, geralmente atribuindo-lhe mais de um sentido. O número de citações foi superior ao total de entrevistas, o que ratifica o caráter híbrido do vocábulo.

Ressaltamos que os nomes verdadeiros dos entrevistados, para resguardar-lhes a identidade, foram substituídos por nomes de árvores. Essa escolha foi feita de forma neutra e dificulta, inclusive, a distinção entre os gêneros (se são homens ou mulheres).

A primeira categoria reuniu oito menções e trouxe a ideia de país relacionada à de estado nacional. Para os professores que fizeram essa correlação, estado nacional e nação guardam sentidos múltiplos. Assim, estado nacional, mencionado como uma forma de organização territorial moderna, difere da ideia de nação por sua materialidade (fronteiras), por apresentar um estado formalmente organizado, possuir soberania e limites territoriais. A soberania desses estados nacionais deve ser reconhecida por outros estados nacionais, a fim de os legitimar coletivamente. A nação, para esses professores, detém um sentido mais justaposto à construção de identidades culturais, linguísticas, históricas, sem serem, necessariamente, soberanas. Para exemplificar: 
Nação é um grupo de pessoas que compartilham determinados preceitos culturais comuns. $O$ estado-nação pressupõe um território, pressupõe um... uma legitimidade do gestor desse território. $O$ estado-nação pressupõe um território e uma legitimidade. [...] Legitimidade significa que ele está lá e não sofre ameaça nenhuma. Porque não existe estado-nação sem soberania, que é sinônimo de país, para mim. (Professor Castanheira)

A complexidade das relações e processos que se tecem em múltiplas escalas torna as singularidades para país maleáveis, ao exigir laços e estratégias ousadas:

Eu acho que dentro da concepção que você tem hoje de país você tem que ter um povo organizado com o estado [...]. Se bem que tem país também com várias nações. [...] Mas o país tal qual a gente imagina tem que ter um estado. Ele tem que ter um poder político organizado, um estado representativo [...], ainda que vivam ali nações diferentes, povos diferentes. Mas ele tem que ter um estado constituído, senão, não é um país. Mas quando você vai pra trabalhar os conflitos, você acaba entrando na nação e no estado. (Professor Juazeiro)

O entrelaçamento dos termos "nação, povo, país e pátria” (Lacoste, 1997, p. 135) desponta no relato a seguir:

Nação... engloba, por exemplo, um [...] na verdade um... um grupo cultural, um grupo étnico, que tem coesões de língua, religião, e compartilhou determinados... fatos históricos comuns. Ele não é necessariamente, não forma necessariamente, eh... um país, com fronteiras etc. e tal. Então, por exemplo, a nação curda. A nação curda ocupa diversos territórios. [...] O estado nacional vem dessa coesão que às vezes é feita à força, como foi o caso da Rússia, ex-União Soviética. (Professor Jatobá)

Na segunda categoria mais citada, a ideia de país traz uma construção abstrata de uma identidade comum ("meu/nós/nosso" país). As manifestações aproximam-se do conceito de nação de Guibernau (1997), enquanto grupo que compartilha uma identidade comum, costumes, tradição, história, língua. Houve uma apropriação de país enquanto algo pessoal, retido e, de certo modo, pertencente ao sujeito:

O nosso país é uma nação. É um Estado com letra maiúscula... com letra maiúscula. As pessoas têm que conscientizar que o país é deles. (Professor Pequizeiro) 
O uso de país é associado também, pelos professores, à proximidade dos alunos com a escala nacional - o Brasil -, nos aspectos que estes presumem análogos ao entendimento e à vivência diária dos estudantes. Nesse exercício, resgatam a analogia entre país e lugar.

Outras vezes, ao aliar país a estado nacional, os entrevistados orientam sua acepção ao conceito de território, distanciando-a de seu sentido original, todavia guardando unidade entre povo/nação, território e, agora, estado.

Outras três categorias equivaleram-se na frequência das citações. A primeira relaciona a ideia de país à de estado nacional, este como distinto de nação, porém empregado para designar e destacar a organização do espaço mundial. Exemplificando:

Olha, porque eu acho que [...] eh, primeiro a questão, assim, da quase extinção do socialismo, que eu acho importante. Eh... da quase totalização do capitalismo na maioria dos países e como isso vai interferir nas questões das relações comerciais entre os países. Eu acho que seriam esses conceitos que ajudariam, assim, a entender o mundo atual. (Professor Limoeiro)

Uma segunda relação recupera a citação de Lacoste (1997), pois alguns docentes, ao adotarem o termo país, parecem evitar definições e discussões acerca do status político e econômico de determinados povos:

Eh... por exemplo, a Guiana Francesa pode-se dizer que é um país. Agora, politicamente, ela é uma... um departamento de ultramar da França. A gente falaria colônia, mas é uma... politicamente, é um departamento do estado francês, um departamento de ultramar. E, no entanto, eu posso dizer, é um país, entendeu? (Professor Jatobá)

Um terceiro grupo de respostas pontua um ligeiro diferencial para o termo país ao tratar de nações e estados nacionais. Os professores declararam não se aterem às diferenças, aplicando o termo tanto para um quanto para o outro sentido, até porque, para eles, nações e estados nacionais são conceitos imbricados entre si:

Agora, nação, eu faço a minha junto com você. [...] Eu estou dando a aula, o menino está aprendendo, a mãe está trabalhando, o outro... E as relações vão acontecendo, e a nação existe. O povo vai criando uma forma de relacionamento ali que fica sobre esse estado nacional, entendeu? [...] A nação pra mim é muito ligada ao povo, às relações, à forma como se vive. Estado é a forma de administrar 
isso tudo. [...] O estado nacional é aquele que administra, que vai policiar, que tem um poder judiciário, legislativo, tudo misturado ali pra tentar fazer, imagina, um guarda-chuvão. O estado nacional é aquilo que vai proteger, entre aspas, tudo que está ali dentro do nosso país. [...] País, quando eu falo país é o conjunto de tudo. Dentro de país tem estado nacional, tem a nação. (Professor Ipê)

Por fim, as respostas relacionaram à palavra país histórias de ficção: País, o conceito de país é [...], por exemplo, Alice no País das Maravilhas. Até... até Alice tem um país (Professor Jatobá). E como didatização de determinado conteúdo: É uma didatização do assunto. Porque quando a gente está estudando na faculdade a gente não ouve muito falar país (Professor Mogno).

Os sentidos transpuseram características do termo a um nível mais metafórico, familiarizando-o com as vivências diárias dos estudantes e com elementos extraídos da mídia e do senso comum.

É exatamente a partir dessa "didatização" que a ideia de país fixa-se e permite construir uma comunidade de sentido ao seu redor. Na escola básica, ela ganha fôlego, mas na graduação procura-se empregar mais os termos nações e estados nacionais (Professor Mogno).

\section{Considerações finais}

País é um dos termos mais usados na escola básica, e, por tal frequência, supõe-se que ele não necessite ser definido e/ou explicado. Estudantes e professores já sabem ao que se reporta "nosso país", que é "soberano", tem "fronteiras definidas", “povo” e "governo próprio”. Esse consenso quanto à comunidade de sentido que país mobiliza leva-nos a crer que, a partir da escola básica, o conceito difunde-se pela sociedade, numa construção e reconstrução de significados, ou, como diz Therborn (1991, p. 21), possibilita que "os seres humanos se constituam como membros conscientes do mundo sócio-histórico”.

Igualmente, seu uso constante permite construir a "interpelação", "uma ilustração, um exemplo adaptado a um modo específico de exposição, suficientemente 'concreta' para ser reconhecida, mas abstrata o bastante para ser pensável e pensada, dando origem a um conhecimento" (Pêcheux, 1996, p. 149). Ela funciona no nível de interpolação de escalas e minimiza efeitos de distanciamento e representação. 
A palavra país favorece, assim, a construção de sentido e significado para as nações e estados nacionais, auxilia em nossa elaboração de sentido para o mundo - dividido em "tantos países, com tantas diferenças e bem poucas similitudes" - e nos concede uma "identidade" e um "sentido de pertencimento territorial-nacional". Associando essa ideia à de construção da ideologia nacional, observa-se que a palavra país tanto confere um sentido quanto oculta o movimento, pois as ideologias

sempre são produzidas, transmitidas e recebidas em situações sociais concretas, materialmente circunscritas, e com base em meios e práticas de comunicação especiais, cuja especificidade material pesa sobre a eficácia da ideologia em questão. (Therborn, 1991, p. 65)

Na escola básica, os sentidos atribuídos à palavra país modificaram-se com as transformações conjunturais das e nas sociedades, sem redução no/do seu uso. Ao contrário, de certo modo, impôs-se uma mudança na escala à qual país se refere, pois ainda designa o local de origem de alguém, e, agora, em escala nacional. Apesar da globalização e de sua aparente preponderância em relação à construção da noção dos sujeitos enquanto "cidadãos do mundo" - ocultando a segregação e discriminação, assim como o fato de que existem pessoas que sequer são cidadãs em seus "países” de origem -, possivelmente é na escola básica, na geografia escolar que uma comunidade de sentido em torno da palavra país se propaga, (re)construindo-a como um semióforo e um híbrido.

\section{Referências}

ANDERSON, Benedict. Comunidades imaginadas: reflexões sobre a origem e a difusão do nacionalismo. São Paulo: Companhia das Letras, 2008.

BAKHTIN, Mikhail Mikhailovich. Marxismo e filosofia da linguagem. 12. ed. São Paulo: Hucitec, 2006.

BHABHA, Homi. O local da cultura. Trad. de Myriam Ávila, Eliana L. de Lima Reis e Gláucia R. Gonçalves. Belo Horizonte: Ed. UFMG, 1998. p. 130.

BOBBIO, N. (Org.). Dicionário de Política. 5. ed. Brasília: Ed. UnB, 2000.

BOLETIM UFMG. Trabalho pedagógico potencializa desempenho no vestibular UFMG. Imprensa Universitária, ano 30, n. 1448, p. 3 a 6, 22 jul. 2004, Belo Horizonte.

. Pesquisa traça perfil escolar de calouro da UFMG. Imprensa Universitária, $\overline{\text { ano 24}}$, n. 1161, p. 4 e 5, 13 ago. 1997, Belo Horizonte. 
BUENO, F. da S. Grande dicionário etimológico prosódico da língua portuguesa. São Paulo: Saraiva, 1968. v. 6.

CARNEIRO, S. M. M. A dimensão ambiental da educação geográfica. Educar, Curitiba, n. 19, p. 39-5, 2002. Disponível em: <http://ojs.c3sl. ufpr.br/ojs2_test/ index.php/educar/article/view/2080/1732>. Acesso em: 10 jan. 2013.

CASTRO, Rita de C. M. L. de. O poder da comunicação e a intertextualidade. 2002. Dissertação (Mestrado em Administração) - Escola de Administração de Empresas de São Paulo, FGV/EAESP, São Paulo, 2002.

CHAUÍ, M. Brasil: mito fundador e sociedade autoritária. São Paulo: Fundação Perseu Abramo, 2000.

COLLINS THESAURUS OF THE ENGLISH LANGUAGE. Complete and Unabridged 2nd Edition, 2002 (C) HarperCollins Publishers, 1995, 2002. Disponível em: <http://www.collinsdictionary.com/english-thesaurus >. Acesso em: 10 dez. 2012.

CUNHA, A. G. da. Dicionário etimológico Nova Fronteira da língua portuguesa. Rio de Janeiro: Nova Fronteira, 1982.

DEL GAUDIO, R. S. Concepções de nação e estado nacional dos docentes de Geografia - Belo Horizonte no final do segundo milênio. Tese. (Doutorado em Educação) - Faculdade de Educação, Universidade Federal de Minas Gerais, Belo Horizonte, 2006. 270f.

(LONGHI), Rogata S. O movimento separatista do Triângulo Mineiro. Lutas Sociais, 4, 1998. Disponível em: <http://pucsp.br/neils/downloads/v4 artigo_rogata.pdf>. Acesso em: 14 fev. 2013.

ENCICLOPÉDIA EINAUDI. Porto: Imprensa Nacional - Casa da Moeda, 2001.

ERNOUT, A.; MEILlET, A. Dictionnaire étymologique de la langue latine histoire des mots. Paris: Librairie C. Klincksieck, 1939.

FERREIRA, Aurélio B. de H. Dicionário da Língua Portuguesa. Rio de Janeiro: Nova Fronteira, 1986.

GUIBERNAU, Montserrat. Nacionalismos - o estado nacional e o nacionalismo no século XX. Rio de Janeiro: Jorge Zahar, 1997.

HAESBAERT, R.; NUNES, S. e RIBEIRO, G. Vidal, Vidais: textos de geografia humana, regional e política. Rio de Janeiro: Bertrand Brasil, 2012.

. Dilema de conceitos: espaço-território e contenção territorial. In: SAQUET, Marcos Aurélio; SPOSITO, Eliseu S. (Org.). Territórios e territorialidades: teorias, processos e conflitos. 1. ed. São Paulo: Expressão Popular, 2009. p. 95-120.

- Da desterritorialização à multiterritorialidade. In: X Encontro de Geógrafos da América Latina. Anais... Universidade de São Paulo, São Paulo, 2005. p. 6774-6792.

HOUAISS, A.; VILLAR, M. de S.; MELLO FRANCO, F. M. de. Dicionário Houaiss da língua portuguesa. 2. ed. Rio de Janeiro: Objetiva, 2009. 
LA BLACHE, Vidal. Os Pays da França. In: HAESBAERT, R.; NUNES, S. e RIBEIRO, G. Vidal, Vidais: textos de geografia humana, regional e política. Rio de Janeiro: Bertrand Brasil, 2012. p. 229-244.

LACOSTE, Yves. Vive la nacion - destin d'une idée géopolitique. Paris: Fayard, 1997.

LAROUSSE. Dicionário de francês. Rio de Janeiro: Larousse do Brasil, 1989.

L'ENCICLOPÉDIA DELLA GEOGRAFIA. Instituto Geográfico De Agostini, Novara, Itália, 1996.

LESTEGÁS, F. R. Concebir la geografia escolar desde uma nueva perspectiva: uma disciplina al servicio de la cultura escolar. Boletín de La A. G. E., 33, p. 173-186, 2002. Disponível em: <http://dialnet.unirioja.es/servlet/articulo?codigo=1122458>. Acesso em: 10 fev. 2013.

LÖWY, Michael. Ideologias e ciência social. São Paulo: Cortez, [1985]2002.

MACHADO, J. P. Dicionário etimológico da língua portuguesa - com a mais antiga documentação escrita e conhecida de muitos dos vocábulos estudados. 4. ed. Lisboa: Livros Horizonte Ltda., 1987. v. 4.

MAGNOLI, D. O corpo da pátria - imaginação geográfica e política externa no Brasil (1808-1912). São Paulo: Moderna, 1997.

MCLELLAN, David. A ideologia. Lisboa: Ed. Estampa, 1987. p. 116.

MOREIRA, Ruy. Da região à rede e ao lugar: a nova realidade e o novo olhar geográfico sobre o mundo. Espaço, tempo e crítica. Revista Eletrônica de Ciências Humanas e Sociais e outras coisas, Niterói, v. 1, n. 1(3), 1/6/2007. Disponível em: <http://www.uff.br/etc/UPLOADs/etc\%202007_1_3.pdf>. Acesso em: 22 nov. 2012.

ORLANDI, Eni P. Discurso fundador: a formação do país e a construção da identidade nacional. Campinas, SP: Pontes, 1993. p. 7.

PAGANO, A.; MAGALHÃES, C. Análise crítica do discurso e teorias culturais: hibridismo necessário. DELTA, São Paulo, v. 21, n. esp., 2005. Disponível em: <http:// www.scielo.br/scielo.php?script=sci_arttext\&pid=S0102-44502005000300004\&lng. PAUL, Robert. Le Petit Robert - Dictionnaire de la Langue Française. Paris: Le Robert, 2000.

PÊCHEUX, Michel. O mecanismo do (des)conhecimento ideológico. In: ZIZEK, S. (Org.). Um mapa da ideologia. Rio de Janeiro: Contraponto, 1996. p. 143-152.

RAFFESTIN, Claude. Por uma geografia do poder. São Paulo: Ática, 1993. v. 29, p. $143-44$.

RANCIÈRE, J. O dissenso. In: NOVAES, Adauto. A crise da razão. São Paulo: Companhia das Letras, 1996. p. 367-382.

SANTOS, Milton. A natureza do espaço - técnica e tempo. Razão e emoção. 3. ed. São Paulo: Hucitec, 1999. p. 258.

THERBORN, Göran. La ideología del poder y el poder de la ideología. 3. ed. México: Siglo Veintiuno, 1991[1987]. 
Rogata Soares Del Gaudio - Graduada em Geografia pela Universidade Federal de Minas Gerais - Mestre em Ciências Sociais pela Pontifícia Universidade Católica de São Paulo - Doutora pela Universidade Federal de Minas Gerais - Membro do Neils da Pontifícia Universidade Católica de São Paulo e Professora Adjunta da Universidade Federal de Minas Gerais.

Doralice Barros Pereira - Graduada em Geografia pela Universidade Federal de Minas Gerais - Mestre em Geografia pela mesma universidade - Doutora em Geografia pela Universidade de Montréal - Professora Associada I da Universidade Federal de Minas Gerais.

Recebido para publicação em 10 de março de 2013

Aceito para publicação em 22 de junho de 2013 